\title{
Hybrid Renewable Energy Power System Model Based on Electrification Requirements of One Fathom Bank Malaysia
}

\author{
S. Sarip, C. G. Abdullah, N. Shafie, N. A. N. Mahadzir, F. Yakob and M. Z. Hassan \\ Razak Faculty of Technology and Informatics, Universiti Teknologi Malaysia, Kuala Lumpur, Malaysia \\ Ocean Thermal Energy Centre, Universiti Teknologi Malaysia, Kuala Lumpur, Malaysia \\ School of Professional and Continuing Education, Universiti Teknologi Malaysia, Kuala Lumpur, Malaysia \\ Malaysia-Japan International Institute of Technology, University Teknologi Malaysia Kuala Lumpur, Malaysia
}

\begin{tabular}{l}
\hline \hline Article Info \\
\hline Article history: \\
Received Jun 2, 2018 \\
Revised Aug 3, 2018 \\
Accepted Aug 10, 2018 \\
\hline
\end{tabular}

\section{Keywords:}

Renewable energy

Power generation

Ocean current

Solar power

One Fathom Bank

\begin{abstract}
Renewable energy resources are becoming inexorably in the field of generating electrical power due to the fast development of technology, given to its advantages over non-renewable energy resources. Though the source is available in enormous amount, energy produced from single renewable energy resources such as tidal current may fluctuate with the time and the hour of the day or month, depending on the tides. Thus, by having a hybrid power system consisting two or more renewable energy resources coming into play at the same time would be more reliable to support the targeted area. However, the availability of renewable energies depends on the climate change, therefore having a storage battery or backup power is often essential. In this case, the main purpose of this research is to develop an off-grid hybrid tidal current and solar power system along with backup power to support One Fathom Bank Lighthouse in Malaysia with the intention to reduce the dependency on diesel generators. Having the ability to evaluate economic and technical feasibility of power system, HOMER software is used to run simulation and analyze the best combination of components to form a hybrid power system for the lighthouse. The results are based on the best components and sizing in compliance with the load demand and diesel fuel consumption to provide a reliable and cost-effective system.
\end{abstract}

Copyright $(2018$ Institute of Advanced Engineering and Science. All rights reserved.

\section{Corresponding Author:}

S. Sarip,

Razak Faculty of Technology and Informatics,

Universiti Teknologi Malaysia,

Kuala Lumpur, Malaysia.

Email: shamsuls.kl@utm.my

\section{INTRODUCTION}

The increasing interest in renewable energy (RE) resources has been observed for several years. Renewable energy resources are well-known as non-polluting, free and continuously available in an enormous amount. These advantages over conventional resources along with the growth and advancement in technology converter have become an alternative solution for many applications in many countries especially in reducing the oil bill [1-4]. Due to the intermittent characteristic of solar radiation which give significant impact to its energy production, atmospheric conditions are one of the major aspects that need to be considered to generate power [3]. In the early stage, producing power with this method was costly, however it offers a cost-effective alternative over an expensive grid. The growth of technology development has produced more and more advance PV technologies and makes it affordable for companies, nor individual to own the system [5] Despite having low maintenance, solar power system is also high reliability and does not release any pollutions to the surrounding. The system life span is also expected to be around 20-30 years and this is why it is labeled as one of the cost-effective system that can be invested through years, which is 
likely to be the most favorable source of energy in these days [6-7]. Nevertheless, most technological innovations that aimed at exploiting resources from the ocean such as tidal current are still in its infancy stage, and sectors have to overcome a number of challenges or obstacles to prove the reliability and affordability of their technologies to harvest the energy from the ocean [8-9].

In this study, One Fathom Bank (OFB) lighthouse or known as Permatang Sedepa in Malay is selected due to its location with high potential of free energies, especially in solar power and tidal current. OFB is located along the international boundary of the Malacca Straits between Malaysia and Indonesia with latitude and longitude of $2^{\circ} 53^{\prime} 00^{\prime \prime} \mathrm{N}$ and $101^{\circ} 00^{\prime} 00^{\prime}$ ' respectively [10]. Few attempts to OFB were conducted and several issues were found during the exploration that need to be addressed promptly, especially on its power utilities availability and maintenance. The Strait of Malacca is a strategic location to harness tidal stream energy due to its strong tidal current resource. With the help of suitable technology converter, the high-speed current along the strait makes it possible to be harnessed and converted into useful energy. However, marine renewable energy (MRE) in Malaysia has not been studied thoroughly especially along the area of the Strait of Malacca. According to the literatures, the water region of the strait covers an area of $65,000 \mathrm{~km}^{2}$ along $850 \mathrm{~km}$ stretch [11-12] and has abundant potential to harness tidal current energy.

The main idea of this research is to propose a hybrid power system in order to reduce the dependency on diesel generators at OFB based on power demand and diesel fuel consumption by harnessing green technologies such as solar power and tidal current. The result of the proposed hybrid model is hoped to be reliable and cost-effective in generating electricity for long period. This study will fully utilize all of the features available in the HOMER software so that more accurate and promising results can be obtained from the simulations. Prior to developing a comprehensive hybrid power system based on renewable energies at OFB, it is important to identify the current status of its main power supply and understand the issues and problems faced by OFB.

\section{EXPERIMENTAL PROCEDURES}

\subsection{Electricity Infrastructure at $\mathrm{OFB}$}

At present, diesel generators are used as main power source supplying electricity to support OFB daily power consumption, but the usage of electricity is strictly for certain electrical appliances only. Priority is given to electrical appliances that is more important such as ensuring the radar system to continuously running so that navigation system will never go off-line, switching on the lights, maintaining the temperature of the room to cool down heated machines with air-conditioned and others. OFB has three diesel generators with $100 \mathrm{~kW}$ power that take turns to operate since only one diesel generator is needed to operate at a time. Other generators are considered as backup when the first generator failed to function. The diesel usage of OFB is estimated to 120 liters per day which cost around RM2.18 per liter [13]. Roughly, the cost of electricity bill at OFB is RM 261.60 per day or RM10.90 per hour. Though diesel generator has always been the first method in solving electricity issue especially for rural areas, however using diesel generator has few drawbacks that gives negative impact to the user in terms of fuel and maintenance cost, and also pollutes the environment. Drawbacks of using diesel generators gives motivation to others in finding a more economical friendly, reliable and cleaner power generation that can meet the power demand at OFB [14].

\subsection{Load Profile of Ofb}

The electrical load of one fathom bank lighthouse can be categorized as residential electrical loads. Generally, off grid residential houses requires electricity for common electrical appliances such as lights and fans. This also falls the same to any lighthouses like OFB. The only difference is that OFB lighthouse is a restricted area thus only a small number of people or workers are allowed to be there. Normally, only two officers will work to guard the lighthouse and very seldom for other people to come to the lighthouse. For instant, researchers who would want to have a site visit to OFB will require to prepare black and white sheet that is approved by the Jabatan Laut Malaysia before going to the site. The electrical power consumption of OFB were taken during site visit and its daily load profile were assumed to be almost constant since only limited activities are allowed at the area. Based on the collected data, the daily average power consumption of OFB is $11.13 \mathrm{kWh} / \mathrm{d}$ with peak power of $0.83 \mathrm{~kW}$.

\subsection{Renewable Energy Resource Assessment}

The average sunshine duration in Malaysia was found to be in the range of 4-8 h/day [15]. In this study, the monthly and annual average of solar radiation data of OFB was obtained from NASA POWER (NASA Prediction of Worldwide Energy Resource) database which can be acquired via HOMER software [16]. Several islands, and countries in the south china sea typically has two monsoon seasons and two 
transitional periods, which has been classified into four period, which are November-February), (May-August), (March-April), and (September-October) [17].

Another important data that is required by HOMER software under tidal turbine window is the monthly average tidal current at OFB. Since Malaysia has two monsoon seasons, and two transitional seasons, and the low and high tides comes twice a day, it is hardly to have an actual average of tidal current speed. However, from the previous studies, it was stated that the lowest tidal current at OFB is $0.80 \mathrm{~m} / \mathrm{s}$ and highest is $1.1 \mathrm{~m} / \mathrm{s}$. Thus, the average tidal current is estimated according to monsoon season but in between the range of highest and lowest tidal current speed measured at OFB.

\subsection{Selecting Components}

In order to create a power system model in HOMER software, it is best to identify the required information that need to be fed into the software. For instance, selecting RE sources, RE components along with its specifications, and etc. A stand-alone hybrid power system combining hydro, PV, wind, battery, and diesel generator was carried out in Bangladesh due to free RE sources at the area. The hybrid system is required to fulfil the requirements of $166 \mathrm{kWh}$ /day primary load and with $21 \mathrm{~kW}$ peak load for 100 households in a remote area. The sizing of the components that complies with the load demand resulted a combination of a hydro turbine of $1.5 \mathrm{~kW}$, one wind turbine of $3 \mathrm{~kW}, 12 \mathrm{~kW}$ PV panels, battery banks and a $10 \mathrm{~kW}$ diesel generator [18]. A similar study was also carried out to find optimal combination and sizing of a standalone hybrid power system in India [19]. High solar radiation and wind speed around the area has attract researchers to convert both energies into useful energy. The optimum hybrid system in this research consists of a $1 \mathrm{~kW}$ PV panels, $3 \mathrm{~kW}$ wind generator, $2 \mathrm{~kW}$ diesel generator, and a $2 \mathrm{~kW}$ converter. The sizing of the components is smaller because the proposed model is analyzed by connecting to a smaller load with daily energy consumption of $11.26 \mathrm{kWh} /$ day with peak load of $2.09 \mathrm{~kW}$ [19]. Both studies indicate that the sizing of the selected components due to the availability of REs around the study area must comply with the load demand to avoid the unmet electric load and capacity shortage [18-19].

In this system, tidal current and solar power are the two selected renewable energy resources and the model consists of five primary components, which includes PV system, hydrokinetic (tidal) turbine, converter, and storage batteries. PV panels and tidal turbine are selected in order to harness the solar power and tidal current energy. Since the daily average power consumption of OFB is $11.13 \mathrm{kWh} / \mathrm{d}$ with peak power of $0.83 \mathrm{~kW}$ therefore the search space for PV panels is varied from $1 \mathrm{~kW}$ to $5 \mathrm{~kW}$ whereas the maximum power output of the selected tidal turbine is $2 \mathrm{~kW}$, and both components has the same lifetime period of 25 years. Batteries and converter are also needed in the system to increase the reliability of the system $[18,20]$ and each component has its own function. Batteries are needed to store the excess power produced by solar panels during the day and outputs from tidal turbine and the stored energy will then be used when the power produced from the energy converter is insufficient to cater the power demand. While converter is needed in order to convert the electricity from AC to DC or vice versa. In many cases, forming an off-grid hybrid power system without diesel generator are rarely to be found, unless the availability of REs around the area are vast enough to be converted by the energy converters. Unfortunately, this system will require diesel generator as contingency plan when the energy produce and energy demand does not meet.

\section{RESULTS AND DISCUSSION}

The results obtained from the simulations are according to the input data that are fed into HOMER software. This study has investigated that the best combination of components is based on the power demand by OFB and the performance of the system that give significant impact in reducing the dependency on diesel generator. Three simulations of different models were carried out and being analyzed according to its performance. These models are differed by the selection of RE resources; a) Solar PV only, b) Tidal turbine only, and c) combining both solar PV and Tidal turbine. Unfortunately, diesel generator is required to be included in each system as contingency plan to ensure continuous electricity supply to the selected area.

The first model consists of photovoltaic (PV) panel with a converter, and diesel generator along with backup storage (batteries bank) as illustrated in Figure 1. Based on the result shown in Figure 2, the top optimized system is when there is no diesel generator being used. However, this system will have electrical complexity whereby it will not be able to meet the electricity demand at all times as shown in Figure 3. Therefore, in order to avoid discontinuous electricity supply, diesel generator is required to be added into the system and the result after adding generator is as shown in Figure 4. Adding generator into the system will not only solving the issue of unmet electricity but also overcoming the capacity shortage of the overall system. Anyhow, the system will require 433litres of diesel fuel per year to keep producing enough amount of electricity as demanded by OFB. 


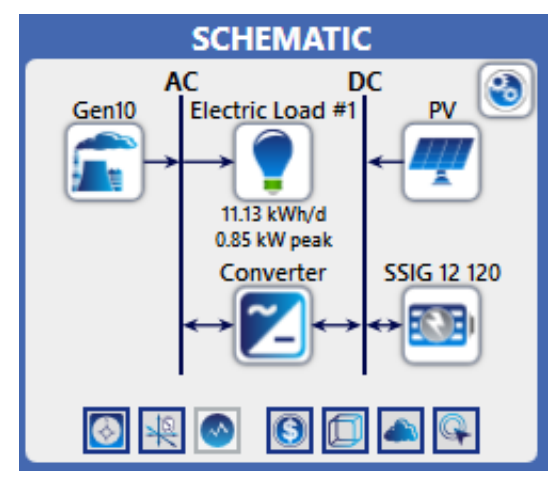

Figure 1. Schematic model of photovoltaic (PV), diesel generator, converter, and battery

\begin{tabular}{|c|c|c|c|c|c|c|c|c|c|c|c|c|c|c|}
\hline \multicolumn{9}{|c|}{ Architecture } & \multicolumn{4}{|c|}{ Cost } & \multicolumn{2}{|c|}{ System } \\
\hline$\triangle$ & 眾 & $\vec{n}$ & 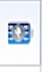 & z & ${ }_{(\mathrm{kW})}^{\mathrm{PV}}{ }^{\mathrm{P}}$ & 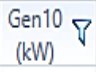 & SSIG $12120 \nabla$ & $\begin{array}{c}\text { Converter } \nabla \\
(\mathrm{kW})\end{array}$ & $\begin{array}{l}\text { COE } \\
(\mathrm{RM})\end{array}$ & $\begin{array}{l}\mathrm{NPC} \\
(\mathrm{RM})\end{array}$ & $\begin{array}{c}\text { Operating cost } \\
\text { (RM/yr) }\end{array}$ & $\begin{array}{c}\text { Initial capital } \\
\text { (RM) }\end{array}$ & $\begin{array}{c}\text { Ren Frac } \\
(\%)\end{array}$ & $\begin{array}{l}\text { Total Fuel } \nabla \\
\text { (L/yr) }\end{array}$ \\
\hline & 嗄 & & 隐 & z & 4.00 & & 16 & 0.760 & $\$ 1.55$ & $\$ 77,774$ & $\$ 3,739$ & $\$ 29,976$ & 100 & 0 \\
\hline & 罳 & in & 略 & $\tilde{z}$ & 3.00 & 10.0 & 10 & 1.80 & $\$ 1.58$ & $\$ 82,072$ & $\$ 4,300$ & $\$ 27,097$ & 77.7 & 433 \\
\hline$\triangle$ & 罪 & in & & z & 1.00 & 10.0 & & 0.00625 & $\$ 4.14$ & $\$ 215,064$ & $\$ 16,010$ & $\$ 10,402$ & 0 & 10,468 \\
\hline
\end{tabular}

Figure 2. Optimization results of photovoltaic (PV), Diesel generator, converter, and battery

\begin{tabular}{|l|l|l|}
\hline Quantity & kWh/yr & $\%$ \\
\hline Excess Electricity & 1,199 & 20.4 \\
Unmet Electric Load & 144 & 3.53 \\
Capacity Shortage & 207 & 5.09 \\
\hline
\end{tabular}

Figure 3. Electrical output of first proposed model without adding generator

\begin{tabular}{|l|l|l|}
\hline Quantity & $\mathrm{kWh} / \mathrm{yr}$ & $\%$ \\
\hline Excess Electricity & 394 & 7.41 \\
Unmet Electric Load & 0 & 0 \\
Capacity Shortage & 0 & 0 \\
\hline
\end{tabular}

\begin{tabular}{|l|l|l|}
\hline Quantity & Value & Units \\
\hline Total fuel consumed & 433 & $\mathrm{~L}$ \\
Avg fuel per day & 1.19 & $\mathrm{~L} /$ day \\
Avg fuel per hour & 0.0494 & $\mathrm{~L} /$ hour \\
\hline
\end{tabular}

Figure 4. Electrical output of first proposed model with generator

The second model consists of tidal turbine, diesel generator, and converter along with backup storage (battery banks) as illustrated in Figure 5. Based on the result shown in Figure 6, the top optimized system is when combining all the components; tidal turbine, diesel generator, battery banks and also a converter. However, by looking at the sizing of the system in Figure 7, the 8 tidal turbine is unable to supply power as much as the first proposed model (solar PV) thus makes it not so favorable due to its high dependency on diesel generator with a total of 793 liters of fuel per annum. 


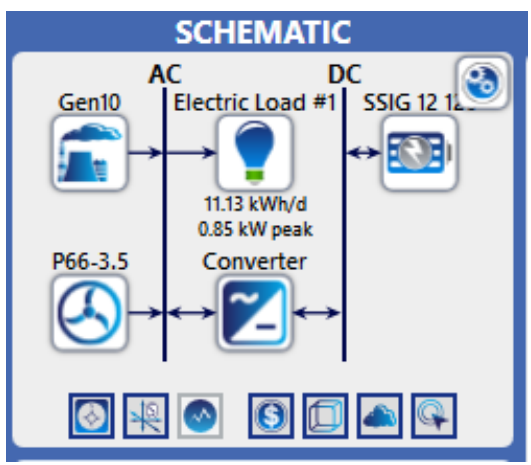

Figure 5. Schematic model of tidal turbine, diesel generator, converter, and battery

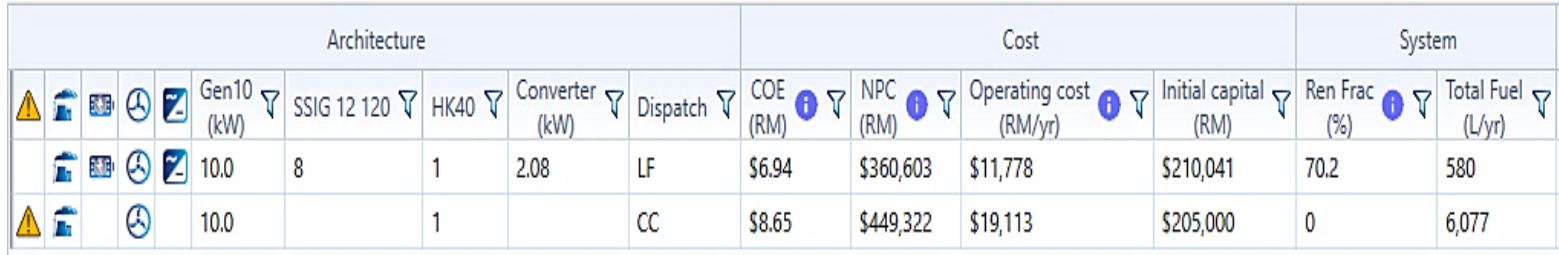

Figure 6. Optimization results of tidal turbine, diesel generator, converter, and battery

\begin{tabular}{|l|l|l|}
\hline Quantity & $\mathrm{kWh} / \mathrm{yr}$ & $\%$ \\
\hline Excess Electricity & 4.57 & 0.101 \\
Unmet Electric Load & 0 & 0 \\
Capacity Shortage & 0 & 0 \\
\hline
\end{tabular}

\begin{tabular}{|l|l|l|}
\hline Quantity & Value & Units \\
\hline Total fuel consumed & 793 & $\mathrm{~L}$ \\
Avg fuel per day & 2.17 & $\mathrm{~L} /$ day \\
Avg fuel per hour & 0.0906 & $\mathrm{~L} /$ hour \\
\hline
\end{tabular}

Figure 7. Electrical output of second proposed model

Since the third model is a combination of both REs technology converter (solar PV and tidal turbine), therefore it can be concluded that this system is a hybrid model system as illustrated in Figure 8. Based on the result shown in Figure 9, the top optimized system is when there is no diesel generator being used. Again, though it combines both RE, however the issue of unmet electrical demand and capacity shortage is still encountered though in a very small amount as shown in Figure 10. Thus, diesel generator is still required to be added into the system with annual diesel fuel consumption of 78.9 liters as shown in Figure 11.

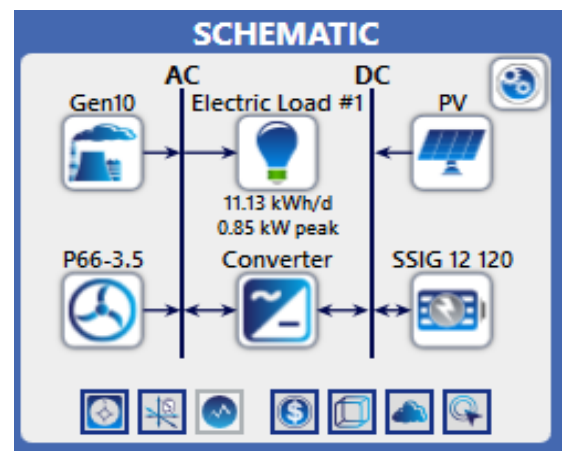

Figure 8. Schematic model of tidal turbine, photovoltaic (PV), diesel generator, converter, and battery 


\begin{tabular}{|c|c|c|c|c|c|c|c|c|c|c|}
\hline \multicolumn{7}{|c|}{ Architecture } & \multicolumn{4}{|c|}{ Cost } \\
\hline$\Delta m$. & 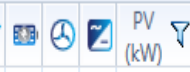 & $\begin{array}{l}\text { Gen10 } \\
(\mathrm{kW})\end{array}$ & SSIG 12120 P & HK40 P & $\begin{array}{c}\text { Converter } \nabla \\
(\mathrm{kW})\end{array}$ & Dispatch $\nabla$ & $\begin{array}{l}\text { COE } \\
(\mathrm{RM})\end{array}$ & $\begin{array}{l}\mathrm{NPC} \\
(\mathrm{RM})\end{array}$ & $\begin{array}{c}\text { Operating cost } \\
\text { (RM/yr) }\end{array}$ & $\begin{array}{c}\text { Initial capital } \\
\text { (RM) }\end{array}$ \\
\hline 里 & 国 (2) 4.00 & & 12 & 1 & 0.646 & $\mathrm{CC}$ & $\$ 6.78$ & $\$ 351,728$ & $\$ 11,180$ & $\$ 208,805$ \\
\hline 果 & 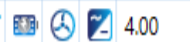 & 10.0 & 8 & 1 & 0.740 & LF & $\$ 6.84$ & $\$ 355,184$ & $\$ 11,209$ & $\$ 211,899$ \\
\hline
\end{tabular}

Figure 9. Optimization results of tidal turbine, photovoltaic (PV), diesel generator, converter, and battery

\begin{tabular}{|l|l|l|}
\hline Quantity & $\mathrm{kWh} / \mathrm{yr}$ & $\%$ \\
\hline Excess Electricity & 4,117 & 48.4 \\
Unmet Electric Load & 1.39 & 0.0343 \\
Capacity Shortage & 3.62 & 0.0892 \\
\hline
\end{tabular}

Figure 10. Electrical output of third proposed model without adding generator

\begin{tabular}{|l|l|l|l|l|l|l|}
\hline Quantity & $\mathrm{kWh} / \mathrm{yr}$ & $\%$ & & Quantity & Value & Units \\
\hline Excess Electricity & 204 & 4.51 & Total fuel consumed & 78.9 & $\mathrm{~L}$ \\
Unmet Electric Load & 0 & 0 & & Avg fuel per day & 0.216 & $\mathrm{~L} /$ day \\
Capacity Shortage & 0 & 0 & & Avg fuel per hour & 0.00900 & $\mathrm{~L} / \mathrm{hour}$ \\
\hline
\end{tabular}

Figure 11. Electrical output of third proposed model with generator

Based on all of the three systems, the simulation shows that diesel generator is still required to be added into the system, however, the diesel generator will only be used when it is crucially needed. The diesel fuel consumption is then simplified and plotted as shown in Figure 12. From the findings, it can be concluded that the least diesel fuel consumption needed is when the system combines all components; tidal turbine, photovoltaic panel, diesel generator, converter and battery banks come into play to generate electricity and comply with the power demand by OFB. Only 78.9 liters of diesel fuel needed per annum. Whereas the highest diesel fuel consumption needed is when it is used together with tidal turbine (second proposed system) to meet the requirement of load demand with total of 793 liters of diesel fuel per year. This makes it ten times diesel fuel more compared to the third proposed system. In a nutshell, it is best to combine all possible RE resources come into play at the same time in order to have higher electricity output from RE resources [21-23] and reduce the need of diesel fuel in the system.

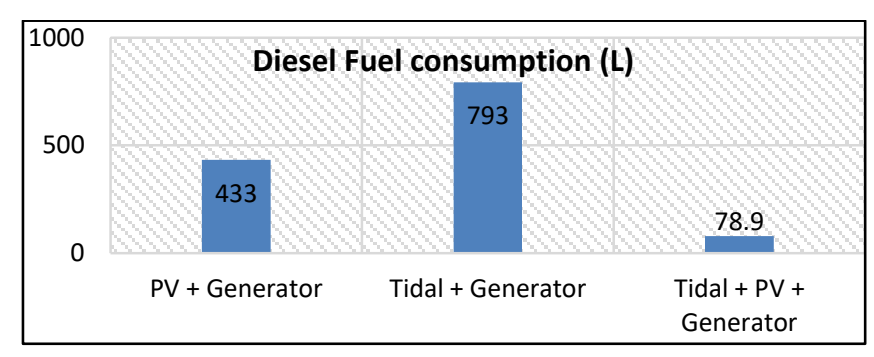

Figure 12. Diesel fuel consumption

By considering the third model as the best proposed power system, comparing its fuel consumption with the existing power supply at OFB (diesel generators) that requires 120 liters per day, it is obvious that a huge amount of money can be saved if the system uses the hybrid model as its electricity generation. Thus, based on the aim of this study, the result obtained from HOMER software is reliable and the proposed hybrid model is a cost-effective system. 


\section{CONCLUSION}

Malaysia has high solar energy potential and the development on applications of photovoltaic technology has been improved from day to day. The fast development of renewable energy technology has allowing us to go deeper in harvesting renewable energy resources so that the usage of finite energy can decrease as long as the clean energy is vast enough to be converted into useful energy. Previous studies have indicated that the tidal current at OFB is great enough to generate electricity with suitable technology converter thus, this information allow us to proceed further in exploring the energy from the ocean, specifically in the Malacca Straits.

This study scrutinizes the most potential configurations at OFB based on the possible combination of solar and tidal current energy resources. The results show that combining both renewable energy (tidal current and solar PV) is the best configuration, however due to some constraint, diesel generator is still needed as contingency plan. In a nutshell, the outcomes from this research can be used as a reference to study deeper in obtaining more reliable and promising results.

\section{ACKNOWLEDGEMENT}

This study is fully supported by the Ministry of Education, and Universiti Teknologi Malaysia (UTM) under Research University Grant (Project no. 17H56) for "Investigate of sustainability hybrid renewable energy system: ocean current turbine and solar power system electrification on one fathom bank Malaysia." We sincerely thank the Research Management Centre (RMC) of Universiti Teknologi Malaysia (UTM) for managing and administering the fund.

\section{REFERENCES}

[1] B. S. Borowy and Z. M. Salameh, "Optimum Photovoltaic Array Size for a Hybrid Wind/PV System". IEEE Trans. Energy Convers. 1994; vol. 9: no. 3: pp. 482-488.

[2] R. Belfkira, C. Nichita, and G. Barakat. "Modeling and optimization of wind/PV system for stand-alone site", in Proceedings of the 2008 International Conference on Electrical Machines. 2008; ICEM'08.

[3] R. Belfkira, C. Nichita, P. Reghem, and G. Barakat. "Modeling and optimal sizing of hybrid renewable energy system". 13th International Power Electron. Motion Control Conference. 2008; pp. 1834-1839.

[4] F. Bonanno, A. Consoli, A. Raciti, B. Morgana, and U. Nocera. "Transient analysis of integrated diesel-windphotovoltaic generation systems”. IEEE Trans. Energy Convers. 1999; vol. 14: no. 2: pp. 232-238.

[5] A. M. A. Haidar, P. N. John, and M. Shawal. "Optimal configuration assessment of renewable energy in Malaysia". Renewable Energy. 2011; vol. 36, no. 2: pp. 881-888.

[6] S. Mekhilef, A. Safari, W. E. S. Mustaffa, R. Saidur, R. Omar, and M. A. A. Younis. "Solar energy in Malaysia: Current state and prospects". Renewable Sustainable Energy Review. 2012; vol. 16: no. 1: pp. 386-396.

[7] R. Saidur and S. Mekhilef. "Energy use, energy savings and emission analysis in the Malaysian rubber producing industries". Apply Energy. 2010; vol. 87: no. 8: pp. 2746-2758.

[8] L. Mofor, J. Goldsmith, and F. Jones. "Ocean Energy:Techmology Readiness, Patents, Deployment Status and Outlook". Int. Renew. energy agency IRENA. 2014; no. August, p. 76.

[9] D. Magagna and A. Uihlein. "Ocean energy development in Europe: Current status and future perspectives". Int. J. Mar. Energy. 2015; vol. 11: pp. 84-104.

[10] G. H. Rayner and R. P. Stranage, "Malacca Strait and West Coast of Sumatera Pilot: United Kingdon Hydrographic Office", 2006.

[11] M. J. Khan, G. Bhuyan, M. T. Iqbal, and J. E. Quaicoe. "Hydrokinetic energy conversion systems and assessment of horizontal and vertical axis turbines for river and tidal applications: A technology status review". Applied Energy. 2009; vol. 86: no. 10: pp. 1823-1835, 2009.

[12] M. I. Yuce and A. Muratoglu, "Hydrokinetic energy conversion systems: A technology status review," Renewable and Sustainable Energy Reviews, vol. 43. pp. 72-82.

[13] KPDNKK- Kementerian Perdagangan Dalam Negeri, Koperasi dan Kepenggunaan. https://www.kpdnkk.gov.my/kpdnkk/oil-price-2018/?lang=en, [Accessed: 1-July-2018]

[14] S. M. Shafie, T. M. I. Mahlia, H. H. Masjuki, and A. Andriyana. "Current energy usage and sustainable energy in Malaysia: A review". Renewable and Sustainable Energy Reviews. 2011; vol. 15: no. 9: pp. 4370-4377.

[15] J. Alia Farhana. "Energy Mix and Alternatives Energy for Sustainable Development in Malaysia". International Student Summit Food, Algriculture Environment New Century. 2009; no. May: pp. 1-9.

[16] P. D. Paul W. Stackhouse, Jr. "NASA Surface meteorology and Solar Energy". 2016; p. 1

[17] M. R. B. Khan, R. Jidin, J. Pasupuleti, and S. A. Shaaya. "Optimal combinations of PV, wind, micro-hydro and diesel systems for a seasonal load demand". Conference Proceeding - 2014 IEEE International Conference on Power and Energy. 2014; PECon 2014: pp. 171-176.

[18] Rahman, M. A., Al Awami, A. T., \& Rahim, A. H. M. A. (2014, April). "Hydro-PV-wind-battery-diesel based stand-alone hybrid power system". In Electrical Engineering and Information \& Communication Technology (ICEEICT), 2014 International Conference on (pp. 1-6). IEEE 
[19] Sandeep, G., \& Vakula, V. S. (2016, March). "Optimal combination and sizing of a standalone hybrid power system using HOMER". In Electrical, Electronics, and Optimization Techniques (ICEEOT), International Conference on (pp. 4141-4144). IEEE.

[20] Homer Energy. "HOMER - Hybrid Renewable and Distributed Generation System Design Software". http://www.homerenergy.com, 2016. [Online]. Available: https://www.homerenergy.com/. [Accessed: 23-Mar2018].

[21] Kusakana, K., Munda, J. L., \& Jimoh, A. A. (2009, September). "Feasibility study of a hybrid PV-micro hydro system for rural electrification”. In AFRICON, 2009. AFRICON'09. (pp. 1-5). IEEE.

[22] Al-Falahi, M. D., Jayasinghe, S. D. G., \& Enshaei, H. (2017). "A review on recent size optimization methodologies for standalone solar and wind hybrid renewable energy system". Energy conversion and management, 143, 252-274.

[23] Siddaiah, R., \& Saini, R. P. (2016). "A review on planning, configurations, modeling and optimization techniques of hybrid renewable energy systems for off grid applications". Renewable and Sustainable Energy Reviews, 58, 376396. 